\title{
Crimean Congo hemorrhagic fever in the COVID-19 pandemic: a case study
}

\author{
Masoud Mardani ${ }^{1}$, Kouros Aghazadeh ${ }^{2}$, Shahriar Nikpour ${ }^{1}$, and Atousa Hakamifard ${ }^{1}$ \\ ${ }^{1}$ Shahid Beheshti University of Medical Sciences \\ ${ }^{2}$ Aja University of Medical Sciences
}

November 11, 2021

\begin{abstract}
In the COVID-19 pandemic, the overlap of clinical features between the other viral infections, make a reliable diagnosis difficult in the initial stage of illness. We describe the first confirmed case of CCHF in Tehran province during this year, who first misdiagnosed as COVID-19 infection.
\end{abstract}

Title: Crimean Congo hemorrhagic fever in the COVID-19 pandemic: a case study

\section{Contributors:}

Masoud Mardani ${ }^{1}$, Kouros Aghazadeh Sarhangipour ${ }^{2,3}$, Shahriar Nikpour ${ }^{4}$, Atousa Hakamifard ${ }^{1 *}$

1. Infectious Diseases and Tropical Medicine Research Center, Shahid Beheshti University of Medical Sciences, Tehran, Iran

2. Infectious Diseases Research Center, AJA University of Medical Sciences, Tehran, Iran

3. Department of Infectious Diseases, Faculty of Medicine, AJA University of Medical Sciences, Tehran, Iran

4. Department of Adult Gastroenterology and Hepatology, Loghman Hakim Hospital, Shahid Beheshti University of Medical Sciences, Tehran, Iran

Running title: CCHF in COVID-19 pandemic

*Corresponding Author: Atousa Hakamifard. M. D.

Infectious Diseases and Tropical Medicine Research Center, Shahid Beheshti University of Medical Sciences, Tehran, Iran.

Tel : +989132291573

Email:atousahakamifard@sbmu.ac.ir

\section{Hosted file}

Main File.docx available at https://authorea.com/users/445666/articles/545114-crimean-congohemorrhagic-fever-in-the-covid-19-pandemic-a-case-study 